\title{
El aumento de las garantías y de los jueces en la protección de los Derechos fundamentales: ¿coexistencia o conflicto entre los sistemas constitucionales internacionales y regionales? -Evolución de una década- Federación Rusa
}

\section{The multiplication of guarantees and the judges in the protection of fundamental rights: coexistence or conflict between constitutional, international and regional systems? -Evolution of a decade- Federation of Russia}

\section{RESUMEN}

Este artículo, presenta un análisis de la actual situación constitucional en Rusia, de acuerdo a los pronunciamientos desarrollados por el Tribunal Constitucional, el derecho público internacional, y la legislación europea; desde la óptica de la protección de los derechos fundamentales, dado el cumplimiento de una década de haber sido incorporada una nueva constitución Ilamada "Ley Fundamental», la cual sustituyo la Constitución vigente desde 1949 hasta el año 2012, marcando un nuevo norte en términos de derechos y libertades. El análisis realizado permite concluir sí esta nueva constitución trae la «fuerza motriz» necesaria para la protección, evolución y desarrollo de los derechos fundamentales de sus ciudadanos.

\section{PALABRAS CLAVE}

Sistemas constitucionales, Derechos fundamentales, Ley Fundamental, Federación Rusa.

\begin{abstract}
This article presents an analysis of the current constitutional situation in Russia, according to the pronouncements developed by the Constitutional Court, international public law and European law; from the perspective of the protection of fundamental rights. Since the fulfillment of a decade have been built in a new constitution called «Basic Law» which replaced the current Constitution from 1949 until 2012, which marked a new option terms of rights and freedoms.

The analysis concluded that the new constitution brings the «driving force» necessary for the protection, evolution and development of the fundamental rights of its citizens.
\end{abstract}

\section{KEYWORDS}

Constitutional systems, fundamental rights, Basic Law and Russian Federation. 


\section{INTRODUCCIÓN}

En la Federación Rusa, la adopción de la Constitución del 12 de diciembre 1993 marcó un punto de inflexión en términos de derechos y libertades. Como todos los países del Este, Rusia ha expresado su deseo de construir un Estado de Derecho después de la caída del régimen soviético, la idea en sí no era nueva. Al final del periodo de Brezhnev, juristas soviéticos comenzaron a invocar el concepto de estado de derecho sobre la base del artículo 4 de la Constitución de 1977¹, bajo la noción de Estado obligado por la ley. Los primeros pasos para su implementación se dieron en 1987 con los esfuerzos de reforma de Gorbachov. Pero la concepción del Estado de Derecho era esencialmente la de una doble responsabilidad: la del Estado para con los ciudadanos y de los ciudadanos para con el Estado (Lesage, 1996). De hecho, la idea de que el poder del Estado, debe estar de acuerdo en someterse a las reglas y que esta sumisión es una garantía fundamental de las libertades públicas -tal como es conocido en la Europa occidental desde hace dos siglos- la cual no penetró ni en la Rusia zarista ni la Rusia soviética. Aunque conceptualmente opuestos, los dos regímenes han ignorado la ley en detrimento de la protección efectiva de los derechos y libertades².

De hecho, después de muchos intentos fallidos en los siglos XVIII y XIX, debido a la incapacidad del régimen zarista a reformarse, las leyes fundamentales de 1906 han sido el punto de partida en la afirmación constitucional de derechos y libertades en Rusia. Entonces las cuatro Constituciones de la
URSS, que sucedieron a la época soviética, ${ }^{3}$ contenían un catálogo de todos los derechos y libertades, algunas disposiciones son incluso de apariencia liberal (Strogovitch, 1964) ${ }^{4}$. Los derechos consagrados, sin embargo, se mantuvieron en gran medida formales, por falta de una legislación que garantice la aplicación y un sistema jurídico fiable que garantice el respeto. Como lo señala el profesor Lesage (1996), las constituciones soviéticas se redujeron a la ficción que oculta el poder del partido y un sistema represivo en parte arbitrario, lo que hizo posible la construcción de mecanismos eficaces de protección.

Para marcar el inicio de la transición a un nuevo sistema político basado en el derecho y que respete los derechos y las libertades, los redactores de la Constitución de 1993 dieron tres pasos importantes. Primeramente fue redactado un catálogo de derechos y libertades muy protectoras y conforme a estándares internacionales. También se han introducido nuevas medidas de seguridad en pro de fortalecer los estados institucionales, federales y federados, para la protección y promoción de los derechos humanos y prevenir su violación. Un tercer paso importante en esta área se ha caracterizado por la apertura del Estado ruso a la justicia internacional al conceder a sus ciudadanos el derecho constitucional de apelar ante los tribunales internacionales una vez agotados todos los mecanismos internos de protección legal. Ciertamente, las experiencias pasadas han demostrado que la afirmación de estas medidas en la Constitución no garantiza la efectividad de los derechos y libertades. No obstante, en opinión de algunos autores rusos, ella trae

\footnotetext{
1 Artículo 4 dedicado legalidad socialista.

2 En el sistema ruso de la autocracia, el zar emitió edictos y su gobierno estaba dando órdenes. En el sistema soviético, el Partido del poder sin límite estaba escondido detrás de unas constitucionales apariencias democráticas. La URSS no tenía la legalidad, pero la «legalidad socialista», Lenin la define como «la interpretación uniforme y la aplicación estricta de los requisitos legales por todos los órganos del Estado, las organizaciones sociales, los funcionarios y los ciudadanos». Para garantizar el seguimiento de la ejecución de los actos jurídicos, creó la Fiscalía, organismo especializado, que se colocó muy por encima del juez.

3 Estos incluyen las Constituciones de la URSS en 1918, 1923, 1936 y 1977.

4 Dos grupos de derechos fueron distinguidos: los derechos políticos (libertad de expresión y la libertad de la prensa, mítines y reuniones de la libertad, la libertad de conciencia, el derecho a ser elector y elegible para los órganos de representación y soviéticos organizaciones sociales, la inviolabilidad de la persona) y los derechos sociales (derecho al trabajo y el derecho al descanso, el derecho a la educación y la atención médica gratuita, el derecho al seguro de pensiones y la seguro o incapacidad). La igualdad de derechos de los ciudadanos de todas las razas y nacionalidades y de las mujeres y los hombres en todos los ámbitos de la vida pública también estaba garantizada.
} 
la «fuerza motriz» necesaria para su protección, evolución y desarrollo, que no existe en los textos constitucionales anteriores.

\section{CONTENIDO Y APLICACIÓN DE CATÁLOGOS DE PROTECCIÓN DE LOS DERECHOS FUN- DAMENTALES}

\section{A. Catálogo de protección normativa de los dere- CHOS FUNDAMENTALES APLICABLES EN EL SISTEMA JURÍDICO}

\subsection{El Catálogo Federal}

La Constitución de la Federación Rusa contiene un capítulo dedicado a los derechos y libertades, su ámbito de aplicación y el alcance de las limitaciones permisibles se pueden encontrar en el Capítulo II denominado "Los derechos y libertades del hombre y del ciudadano». Este es el capítulo más extenso, pues contiene cuarenta y ocho artículos sobre los ciento treinta y siete que componen el texto constitucional. Durante los trabajos preparatorios, la redacción de las disposiciones relativas a los derechos y libertades ha sido objeto de especial atención. La mayoría de los artículos contienen de dos a cinco renglones. Las disposiciones sobre los derechos y libertades también están presentes en otros capítulos de la Constitución. Los constituyentes rusos han optado por introducir en el capítulo I del texto constitucional, dedicado a los «Fundamentos del orden constitucional», que define los principios fundamentales de la política estatal en materia de derechos y libertades. El artículo 2 de la Constitución de 1993 que establece, por primera vez en la historia constitucional de Rusia «al hombre, sus derechos y libertades como valor supremo». El reconocimiento, el respeto y la protección de los derechos y libertades «es una obligación del Estado». El artículo 6, a continuación establece el principio de igualdad de todos los ciudadanos de la Federación de Rusia a sus derechos y obligaciones. El principio del Estado social «cuya política es establecer las condiciones que garanticen una vida digna y el libre desarrollo del hombre» prevista en el artículo 7 de la Constitución. En segundo lugar, el artículo 8 reconoce, el apoyo a la libertad de la actividad económica y la protección de todas las formas de propiedad. Se trata de disposiciones importantes, por el hecho que ellas reconocen nuevas libertades, rechazadas por el sistema soviético, al considerarlas pertenecientes a la ideología burguesa.

Leyendo el capítulo segundo de la Constitución rusa, dedicado a los derechos y libertades, se identifica tres ideas dominantes: i). La dignidad humana; ii). La libertad; y iii). La igualdad. El principio de la dignidad humana se proporciona en particular en el artículo 21. Esto es, obviamente, una cláusula general, pero su introducción en el texto de la Constitución aparentemente rechazó las prácticas del pasado y asegurará su no repetición. El primer párrafo establece el deber de protección: «La dignidad de la persona está protegida por el Estado. Nada puede justificar su restricción». En el segundo párrafo de este artículo, el constituyente de Rusia llevó a cabo una serie de actos ahora prohibidos por la ley suprema: «Nadie será sometido a torturas, violencia, tratos brutales o castigos que degraden la dignidad humana. Nadie puede estar sin su libre consentimiento, sometido a experimentos médicos, científicos u otros similares».

El principio de la libertad del hombre, esta invocado directa o indirectamente, en muchos artículos, por lo que es posible encontrar: el reconocimiento del derecho de cada uno a la libertad y la inviolabilidad personal (artículo 22, línea 1); la libertad de elegir su nacionalidad (artículo 26, línea 1); la libertad de elegir su idioma de comunicación, la educación, la formación y creación (artículo 26, línea 2); la libertad de circulación y elección de residencia (artículo 27); la libertad de creencias y difusión de convicciones religiosas (artículo 28); la libertad de pensamiento y expresión (artículo 29, línea 1), la libertad de elegir su ocupación, etc.

El principio de igualdad también está consagrado varias veces. En la continuación del citado artículo 6 , el artículo 17 - primer artículo del capítulo dedicado a la Libertades y Derechos - establece, en general, en el segundo párrafo, que «los derechos y libertades fundamentales del hombre son inalienables 
y pertenecen a todos desde el nacimiento». En segundo lugar, el artículo 19 viene con varias aclaraciones para poner un mayor énfasis en el principio de la igualdad: la primera cláusula reconoce «la igualdad de todos ante la ley y los tribunales»; por su parte, el párrafo 2 establece que «el Estado garantizará la igualdad de derechos y libertades del hombre y del ciudadano, independientemente de su sexo, raza, nacionalidad, idioma, origen, estatus oficial, lugar de residencia, actitud hacia la religión, convicciones, pertenencia a asociaciones, y otras consideraciones». En segundo lugar, se establece que «cualquier forma de limitación de derechos por razones de tipo social, racial, nacional, idioma o religión está prohibida»; el párrafo tercero se dedica al principio de igualdad entre hombres y mujeres: «El hombre y la mujer tienen los mismos derechos, igualdad de libertades e igualdad de oportunidades para ejercerlos». Este artículo deja parecer a la vez el miedo de los constituyentes rusos de dejar un lugar a interpretaciones múltiples, que los llevaron a abogar por una enumeración exhaustiva de los diferentes casos, sino también su lucidez porque prevé la existencia o la posible aparición de situaciones imprevistas. Introduciendo la cláusula "otras consideraciones», ellos suprimieron el riesgo de interpretaciones divergentes 0 abusivas porque en virtud del artículo 125 de la Constitución, el Tribunal Constitucional es el único órgano autorizado para hacer la revisión constitucional y/o emitir una interpretación oficial de las disposiciones constitucionales.

El principio de igualdad también se menciona en todos los artículos sobre los derechos sociales (artículos 37 a 43), con el uso del pronombre «cada uno». De este modo, los constituyentes rusos querían establecer la continuidad de las políticas sociales de la era soviética, firmemente anclados en la distribución equitativa de la riqueza y la justicia social, y así evitar una ruptura repentina con el antiguo sistema.

También se observa que el catálogo constitucional contiene una lista exhaustiva de los derechos y libertades relacionados con las áreas donde ocurren violaciones de derechos humanos con mayor frecuencia, como la prohibición de la detención y la detención arbitraria, vista con la limitación a las 48 horas de los períodos de detención sin sentencia judicial (artículo 22, línea 2), la prohibición de entrar en una casa contra la voluntad de las personas que viven allí, excepto en los casos establecidos por la ley o sobre la base de una decisión judicial (artículo 25), el derecho a hablar con un abogado en el momento de la detención (artículo 48), sino también el principio de la presunción de inocencia (artículo 49), la prohibición de uso de las pruebas obtenidas con violación de la ley, el derecho de recurrir ante una instancia judicial superior (artículo 50), el derecho a una indemnización por parte del Estado por los daños causados por las acciones (u omisiones) de órganos de poder del Estado y sus funcionarios (artículo 53).

La Constitución también contiene los llamados derechos de tercera generación. El artículo 42 establece el derecho de toda persona a un medio ambiente favorable, información fiable sobre su estado y para reparar el daño a su salud o la propiedad por delito ecológico. La Ley Fundamental prevé además el deber de toda persona a proteger la naturaleza y el medio ambiente y la conservación de los recursos naturales (art. 58). El texto constitucional contiene otras obligaciones como requisito para los padres para mantener y educar a sus hijos y, por el contrario, los mayores de 18 años capaces de trabajar pueden asegurar el mantenimiento de sus padres no aptos para el trabajo (artículo 38), la obligación de pagar los impuestos que establece la ley (artículo 57) o la de la defensa de la Patria (artículo 59).

En cuanto a los destinatarios de los Derechos y Libertades, el título del capítulo 2 indica que se trata de los derechos y libertades fundamentales del hombre y del ciudadano. Se está entonces ante una distinción entre los derechos y las libertades disponibles para cada persona y aquellos que disponen exclusivamente los ciudadanos. Este enfoque es evidente, desde la ratificación por Rusia de las convenciones internacionales sobre los derechos del hombre imponiendo al país la obligación de garantizar determinados derechos y libertades de la persona. La aproximación tradicional de las Constituciones soviéticas, según la cual los derechos fundamentales fueron otorgados por el Estado a los ciudadanos, y no a cada ser humano, en contrapartida 
del cumplimiento de sus deberes ha sido entonces abandonada. Después de leer el capítulo 2, se puede observar que la mayor parte de los derechos y libertades consagrados en ella no están condicionados por la posesión de la ciudadanía ${ }^{5}$.

La Constitución rusa no indica claramente si las personas morales también son sujetas de derechos fundamentales. El título del capítulo 2, que evoca «el hombre y el ciudadano» parece sugerir que sólo las personas físicas pueden ser portadores de los derechos fundamentales. Al mismo tiempo, la Constitución define ciertos derechos básicos que se refieren a sujetos colectivos (partidos políticos, sindicatos...). Además, está claro que ciertos derechos fundamentales, como el derecho a la propiedad o la libertad de empresa, deben, por la naturaleza del sistema económico, aplicarse no sólo a los individuos sino también a los actores económicos. El catálogo de derechos y libertades de la Constitución rusa es bastante completo y cumple con las normas internacionales relacionadas en esta área, que sirvieron como fuentes de referencia para los constituyentes.

\subsection{Las fuentes de referencia}

Como fue el caso en las nuevas democracias ha surgido a raíz de la caída del muro de Berlín, el proceso constituyente fue apoyado por Rusia, pero también supervisado e influenciado por la Comisión Europea para la Democracia a través del Derecho. ${ }^{6}$ En efecto, mediante la producción de una serie de estudios en el ámbito electoral, sobre el referéndum, la supremacía de los tratados en materia de derechos y libertades fundamentales, la protección de las minorías, la actividad de esta última no fue redu- cida a un papel asistencial. Ella ha «marcado» de alguna manera el camino a seguir para traer nuevos ordenamientos jurídicos internos de conformidad con todos los acuerdos internacionales -requisito obligatorio para obtener "la etiqueta democrática» (Luchaire, 2008)-. Los constituyentes rusos han recurrido al modelo occidental de democracia constitucional pluralista por dos razones principales. En primer lugar, porque correspondía a una profunda aspiración política: parecía la única capacidad operativa para dar vida al cambio ideológico, sobre todo por la velocidad de las tasas de transición, ya que las sucesivas crisis políticas, no ofrecían otras alternativas. $Y$ en segundo lugar, porque también ha sido impuesto, de alguna manera, que la elección de estos principios era un requisito previo esencial para la admisión de la Federación de Rusia en el sistema de las organizaciones internacionales ${ }^{7}$. En la Declaración de Viena del 9 de octubre de 1993, el Consejo de Europa fortaleció sus requisitos -haciéndolos «más elevados que los impuestos hasta el momento por los países candidatos» (Claret, 1998)subordinando la adhesión de los Estados a la integración del patrimonio constitucional Europeo ${ }^{8}$.

La Comisión de Venecia ha también examinado si los diversos proyectos constitucionales presentados por Rusia de conformidad «con las normas del patrimonio constitucional europeo, incluidos los principios que emergen de la CEDH», presentando cada vez comentarios con el fin de mejorar disposiciones que presentaban problemas (Dictamen de la Comisión de Venecia 11/09/93). En opinión de la entrada en vigor de la Constitución de 1993, los expertos de la Comisión llegaron a la conclusión de que «el

5 Estos incluyen sus artículos 59 a 63 de la Constitución.

6 Llamada la "Comisión de Venecia», que cada año en cada una de las cuatro estaciones (marzo, junio, octubre y diciembre) se llevan a cabo en Venecia, se estableció en 1990 como un «instrumento de ingeniería constitucional de emergencia en un contexto de transición democrática».

7 El Consejo de Europa propone como una escuela de democracia, imponiendo sus propias reglas. Se ofreció a los recién llegados la oportunidad de unirse a muchas convenciones, incluida la protección de las minorías, tema especialmente sensible en los países post-socialistas donde la conflictividad de étnias aúmentaba los niveles de preocupación.

8 La Declaración de Viena de 9 de octubre de 1993 establece que la adhesión presupone que el Estado ha traído sus instituciones y sistema jurídico, de conformidad con los principios básicos de un Estado democrático bajo el imperio de la ley y el respeto a la dignidad humana hombre. El sufragio universal, la libertad y la equidad de las elecciones, la garantía de la libertad de expresión, la protección de las minorías nacionales y el respeto de los principios del derecho internacional también se erigieron a «factores decisivos en la evaluación de la aplicación». 
contenido de la Ley Fundamental responde en principio, con los criterios de una constitución moderna» (Dictamen de la Comisión de Venecia el 16 de marzo de 1994). En opinión de los expertos, la Constitución de Rusia «(...) reconoce y garantiza todos los derechos fundamentales y sociales que se encuentran comúnmente en las constituciones democráticas modernas» y "debería ayudar a establecer un orden político democrático basado en los derechos del hombre y la preeminicencia del derecho» (Dictamen de la Comisión de Venecia 16/ 03/1994).

Las exigencias europeas en materia de derechos del hombre, han sido plenamente respetadas, lo que explica la incorporación consecuente de derechos y libertades en el texto constitucional. Aunque la Convención Europea de Derechos Humanos siguió siendo la fuente preferida de inspiración para los constitucionalistas rusos, las fuentes de los derechos y libertades consagrados en la nueva Constitución son heterogéneas. Los electores rusos recurrieron a todos los tratados internacionales. En el artículo 17 de la Constitución rusa, incluso se especifica que "los derechos humanos y los derechos civiles son reconocidos y garantizados en la Federación Rusa, de conformidad con los principios universalmente reconocidos en las normas del derecho internacional.» Como se ha visto, ciertos derechos y libertades, por tanto, van más allá de las normas europeas, tales como el derecho a un seguro de salud y de la seguridad social y el derecho a un medio ambiente sano y la información completa sobre el estado del medio ambiente. Del mismo modo, el principio de igualdad, que constituye la base de la Constitución rusa, figura en el artículo 26 del Pacto Internacional de Derechos Civiles y Políticos, pero no pretende ser una garantía general en el CEDH, no estando garantizado el principio de igualdad más que en el goce de los derechos y libertades reconocidos en la Convención, en el artículo 14.
El antiguo juez constitucional Toumanov (2006) también ha destacado que la Constitución de Rusia de 1993 se basa en el modelo de las constituciones democráticas consagradas en Europa Occidental después de la Segunda Guerra Mundial: la Ley Fundamental de la República Federal Alemana de 1949, las Constituciones de la Francia de 1958, de Italia 1947, de España en 1978. Al leer el texto constitucional de la Federación de Rusia permite resaltar ciertas semejanzas. El artículo 17 de la Constitución, por ejemplo, en el apartado 3 expresa que «el ejercicio de los derechos y libertades del hombre y del ciudadano no debe violar los derechos y libertades del otro». Estas formulaciones hacen, de manera evidente referencia a los artículos IV y V de la Declaración francesa de los Derechos Hombre y del Ciudadano de 1789. En segundo lugar, el artículo 18 de la Constitución de Rusia proclama que «los derechos y libertades del Hombre y del Ciudadano tienen un efecto directo». Esta fórmula ha modelado obviamente en el artículo $1 \S 3$ de la Ley Fundamental de la República Federal de Alemania, según la cual todas las normas contenidas en el Título 1 «Los derechos fundamentales» constituyen derecho directamente aplicable. La heterogeneidad de las fuentes explica, en parte, la abundancia del contenido del capítulo dedicado a los derechos y libertades, que también puede experimentar algunas restricciones.

\subsection{Las condiciones de restricción}

El problema del alcance autorizado de restricciones de los derechos fundamentales ocupa un lugar central en el debate sobre este tipo de derechos. En la Federación de Rusia, país que han conoció graves violaciones de los derechos y libertades, la definición del marco y los principios de la limitación de los derechos fundamentales debían estar contenidos en las disposiciones constitucionales. Esto es lo que se ha hecho. La Constitución de 1993 establece varios niveles de protección. En primer lugar, en virtud del artículo 135 de la Constitución Federal, Capítulo 2, dedicado a los derechos y libertades es

9 Los otros dos capítulos relevantes son: Capítulo 1 «Los fundamentos del orden constitucional» y en el capítulo 9 «Las enmiendas constitucionales y la revisión de la Constitución». 
uno de los tres capítulos que no puede ser revisado por la Asamblea Federal (la Duma del Estado y el Consejo de la Federación reunidos) $)^{9}$. Si la propuesta de revisión de las disposiciones que pertenecen a uno de los tres capítulos en cuestión está apoyada por el voto de las tres quintas partes de todos los miembros del Consejo de la Federación y los diputados a la Duma del Estado, una asamblea constitucional es convocada. En el caso de que esta última acepta la propuesta, se procederá con el desarrollo de un nuevo proyecto de constitucional. Deberá ser adoptada por la Asamblea Constitucional por una mayoría de dos tercios de todos sus miembros o sometido a referéndum. En este último caso, la Constitución de la Federación Rusa, se considerará aprobada si más de la mitad de los votantes que participaron en la votación han votado por ella, a condición de que la mitad de los votantes se hayan presentado a las urnas. Este procedimiento es difícil de implementar, lo que complica la tarea del Parlamento en el caso en que el desee hacer un supresión o revisión significativa de los Derechos y Libertades.

En segundo lugar, la Constitución Federal contiene varios artículos que establecen los límites de las restricciones que se pueden ser aportados a los derechos y libertades garantizados. Ella distingue dos categorías de derechos: los derechos intangibles y los derechos y libertades, que, en casos específicos, pueden sufrir limitaciones. Por lo tanto, de acuerdo con lo dispuesto en el artículo 56, línea 3, «los derechos y libertades previstos en los artículos 20, 21, 23 (1), 24, 28, 34 (1), 40 (1), 46 a 54 de la Constitución de Rusia no pueden ser objeto de limitaciones». Como lo podemos constatar, la intangibilidad está garantizada para un número significativo de derechos: dieciséis de los cuarenta y ocho artículos que componen el capítulo 2 sobre los derechos y libertades están relacionados. Si la prohibición de restringir ciertos derechos, como el derecho a la vida, el respeto por la dignidad humana, la protección judicial, resaltan de las cláusulas generales típicas, lo que no ocurre con otras. Los constituyentes rusos, por ejemplo, han descartado cualquier limitación del derecho a la vivienda, lo que le valió a la Constitución una serie de críticas.
La Constitución Federal viene enseguida con precisiones con el fin de encuadrar las medidas de restricción que podrían ser aportadas a los otros derechos. Desde el punto de vista formal, estas restricciones no pueden estar previstas más que «(...) por la ley federal». A nivel jurídico, esta garantía está directamente relacionada con el principio general según el cual el reglamento de la situación jurídica de la persona en el estado se encuentra bajo una materia reservada a la ley. A nivel político, esto significa que las restricciones de los derechos y libertades deben ser introducidas por el Parlamento, por lo tanto, una entidad que tiene sesiones públicas es responsable, ante los electores en virtud de su elección por sufragio. Desde el punto de vista material, las restricciones pueden ser introducidos únicamente con el fin de proteger a uno de los cinco valores enumerados en el artículo 55, línea 3: i). La protección de los fundamentos del orden constitucional; ii). La protección de la moral; iii). Protección de la salud; iv). La protección de los derechos e intereses legales de los demás; v). La garantía de la defensa y la seguridad del estado. Cada ley que introduce una restricción de los derechos y libertades debe buscar la protección del «interés público», en referencia a uno de los cinco dominios particulares mencionados anteriormente. Sin este vínculo material, la introducción de tal restricción no tiene autoridad constitucional y la prestación se convierte, por lo tanto, en inconstitucional.

Una situación particular de limitación de derechos fundamentales tiene lugar cuando las medidas de emergencia son introducidas, es decir, cuando en el Estado aparece en situación amenaza excepcional cuya resolución requiere el uso de medios especiales. La cuestión del estado de urgencia encuentra una regulación bastante general en la Constitución rusa. El constituyente dispone que el estado de urgencia pueda ser introducido cuando sea necesario para garantizar la seguridad de los ciudadanos y para garantizar la protección del orden constitucional. Del mismo modo, la introducción de un estado de urgencia no puede tener lugar más que en virtud de una ley federal, que especificará las limitaciones que se aplicarán a los derechos y las libertades fundamentales y la duración de sus efectos. Como se ha señalado por 
los expertos de la Comisión de Venecia, la elección de las disposiciones más generales podría abrir el camino a los abusos de poder por parte de los poderes legislativo y ejecutivo. El control estricto de estos límites se encuentra dentro de la jurisdicción de la Corte Constitucional, que debe garantizar el respeto de los principios de proporcionalidad y oportunidad.

\subsection{Los catálogos de los individuos de la Federación}

La Constitución de Rusia contiene tres artículos de aplicación de la distribución de poderes entre el gobierno federal y sus individuos. Dos de los tres artículos comprenden disposiciones relativas a los derechos y las libertades. El artículo 71 relativo a las competencias exclusivo del gobierno federal prevé que este último reglamenta y protege los derechos y libertades del hombre y del ciudadano y los derechos de las minorías nacionales. El artículo 72, que establece las competencias conjuntas, dispone que la protección de los derechos y libertades del hombre y del ciudadano y los derechos de las minorías nacionales sean competencia del estado federal y de sus entidades federadas. El artículo 73 relativo a las competencias exclusivas de los sujetos de la Federación, no tiene ninguna disposición que se relacione con los derechos y las libertades.

Del mismo modo, la Constitución federal no impone ninguna condición para el contenido de las leyes fundamentales de las entidades federadas. El artículo 66 se limita a afirmar en sus dos primeras líneas que en las Repúblicas federadas son adoptadas las constituciones y las otras entidades federales adoptan Estatutos. Los sujetos federados tienen, por tanto, la libertad de decidir sobre la estructura y el contenido de su norma fundamental. Esta libertad es aún limitada, ya que, según el artículo 4 , párrafo 2 del texto constitucional federal, la Constitución de la Federación de Rusia y las leyes federales prevalecen sobre todo el territorio de la Federación Rusa. El gobierno federal también tiene un control de proceso o monitoreo. Sin embargo, de conformidad con el artículo 125, apartado 2 literal c de la Constitución de 1993, el Tribunal Constitucional de la Federación de Rusia se pronuncia sobre la conformidad con la
Constitución federal y las constituciones de las repúblicas y de los estatutos de los otros sujetos federados.

En cuanto al contenido real de las leyes fundamentales de los sujetos federados, sería imposible hacer un análisis de cada uno debido a su gran número. Sólo la Constitución de la República de Sajá, la Constitución de la República de Daguestán y el estatuto de la ciudad de Krasnodar fueron seleccionados para este estudio porque tienen, en nuestra opinión, las características que marcan tanto la originalidad y complejidad del federalismo ruso. La primera observación que se puede hacer después de la lectura de los tres textos es que hay una gran diferencia entre las dos Constituciones y Estatuto. Este último es mucho más corto y no contiene un capítulo dedicado específicamente a los derechos y libertades fundamentales. Se establece en su artículo 12, línea 1 , que los ciudadanos de la Federación Rusa o residente ubicados en el territorio de Krasnodar disfrutan de los derechos y libertades del hombre y del ciudadano garantizados por la Constitución de la Federación Rusa, las leyes federales, el presente Estatuto y las leyes de la región (Krai). La Sección 2 está dedicada a las personas que no tienen la ciudadanía rusa. Ellos disfrutan de los derechos y libertades garantizados por la Constitución Federal, las leyes federales y los tratados internacionales. Por el contrario, en el capítulo 2, que consta de seis artículos, se dedica a la participación de los ciudadanos en la administración de los asuntos de la entidad, mientras que la Constitución Federal dedica sólo dos artículos al respecto.

En términos de las dos Constituciones federadas, hay mucho en común con la Constitución Federal, tanto en su nivel estructura como en su contenido. Los dos han retomado el artículo 2 de la Constitución Federal que establece que «el hombre, sus derechos y libertades constituyen el valor supremo». La Constitución de la República de Sajá, lo establece en su artículo 2 y la Constitución de Daguestán lo hace en el artículo 3. En segundo lugar, las dos Constituciones estudiadas dedican su Capítulo II a los derechos y libertades, en la imagen de la Constitución Federal. El Constituyente de la República de 
Daguestán ha elegido el mismo número y el mismo título «Derechos y libertades del hombre y del ciudadano», compuesto por treinta y cinco artículos. En términos de la Constitución de la República de Sajá, también, dedica el Capítulo 2 a los derechos y libertades, pero los llama «los derechos, libertades y deberes del hombre y del ciudadano», que contiene veinticinco artículos.

En cuanto al contenido, las dos Constituciones contienen evidentemente los derechos que figuran en la Constitución Federal. Sin embargo, la lectura de los textos revela su adaptación a la especificidad del contexto en el que se aplican. En Daguestán, donde el tema de las minorías es muy sensible, el constituyente consagra desde el capítulo I de la Constitución, los principios de igualdad, el respeto a la identidad cultural, nacional e histórica (artículos 5 y 6). En el artículo 48, está previsto que la enumeración en la Constitución de la República de Daguestán de los derechos y libertades fundamentales no se interpretará como una negación o restricción de los derechos y libertades garantizados en la Constitución de la Federación Rusa y otros derechos y libertades reconocidos universalmente.

La originalidad de la Constitución de la República de Sajá se encuentra, concretamente, en el artículo 6. De acuerdo con lo dispuesto en este artículo, están prohibidas en el territorio de la República cualquier actividad concerniente en el almacenamiento de residuos nucleares, químicos o bacteriológicos así como las pruebas de armas de destrucción masiva, ya que van en contra de los derechos e intereses garantizados al pueblo. Estas disposiciones reflejan la importancia del papel que desempeñan los componentes federados. A pesar de un federalismo muy centralizado, aún pueden optar por algunas decisiones para defender los intereses de la entidad y de sus habitantes.

\section{B. Catálogos complementarios o supletivos}

El artículo 17 de la Constitución rusa establece en su primer párrafo que «en la Federación Rusa, se reconoce y garantiza los derechos y libertades del hombre y del ciudadano de acuerdo con los principios y normas universalmente reconocidas del derecho internacional». La Ley Fundamental añade, en el artículo 55, línea 1 que «la inclusión en la Constitución de la Federación Rusa de los derechos y libertades fundamentales no se interpretará como una negación o limitación de otros derechos y libertades de los Hombre y del Ciudadano universalmente reconocidos». Aunque la lista de los derechos y libertades de la Constitución de Rusia es muy completa, estos dos artículos permiten una apertura a otras fuentes del derecho, que los jueces rusos utilizan con bastante frecuencia.

Por lo tanto, la práctica judicial tiene más de una docena de resoluciones en las que el Acuerdo de Asociación y Cooperación (ACC) en 1994, así como otros acuerdos sectoriales entre la UE y Rusia (Kellermann, 2005) han sido aplicadas por los tribunales rusos y más de un centenar de casos en los que se hace referencia a la ley de la Unión Europea. Muy a menudo, las disposiciones de la legislación de la UE son aplicados por los tribunales de arbitraje en asuntos en materia comercial, aduanera y fiscal, ofreciendo así garantías de fortalecimiento a la protección de los derechos individuales (Kalinichenko, 2007). Sin embargo, como se ha señalado por el Profesor Kovalkova (2005), son los individuos privados que se convierten en sujetos y destinatarios del Acuerdo, mientras que el papel del Estado, que también es el tema principal del derecho internacional, es limitado el desarrollo de mejores condiciones legales para una actividad independiente y eficaz de los particulares.

De conformidad con el Acuerdo de colaboración y cooperación, Rusia debe llevar gradualmente su legislación compatible con las normas y estándares de la Unión Europea. El artículo 55 de la CPA prevé 15 dominios de vinculo de legislaciones: el derecho de sociedad, el derecho bancario, la contabilidad y la fiscalidad de las empresas, la protección de los trabajadores en el lugar de trabajo, los servicios financieros, las normas de competencia, la contratación pública, la protección de la salud y la vida de las personas, animales y plantas, medio ambiente, la protección del consumidor, la fiscalidad indirecta, la legislación aduanera, las reglas y 
normas técnicas, las leyes y reglamentos nucleares, y de transporte.

Los estándares de la OMC y la OCDE también ejercen una influencia especial sobre el trabajo de los jueces rusos, al igual que las de otras organizaciones internacionales. Esto se aplica con mayor frecuencia a las normas de la Organización Marítima Internacional (OMI), la Organización de Aviación Civil Internacional (OACI), la Organización Internacional del Trabajo (OIT), la Comisión Económica de las Naciones Unidas para Europa (CEPE), la Organización Mundial de la Salud (OMS), etc. Pero la principal fuente de inspiración sigue siendo el Convenio Europeo de Derechos Humanos y la jurisprudencia de la Corte de Estrasburgo.

En Rusia, los jueces constitucionales han tenido un papel muy importante durante el proceso de reforma del sistema normativo, canalizando el trabajo del legislador y conduciéndolo para que cumpla con los estándares europeos. El estudio de la jurisprudencia de la Corte Constitucional hecho entre 1998 y 2002 muestra que se analizaron todas las preguntas importantes sobre los derechos procesales a través del derecho convencional. Así que cuando se le preguntó acerca del principio de contradicción e igualdad entre las partes, el Tribunal Constitucional (Sentencia del 2 de julio de 1998) se basó en los principios establecidos en el artículo 6.1 y 3 de la CEDH y los previstos en el artículo 2-1 del Protocolo $n^{0} 7$. Ella repite los mismos argumentos en otras dos sentencias. En la primera, de fecha 10 de diciembre de 1998, el juez constitucional lo hizo para invalidar las disposiciones del artículo 335-2 del Código de Procedimiento Penal de la RSFSR, que habilitaban el tribunal estatuyendo en casación autorizar o no, a su criterio, la presencia del acusado en las audiencias. En la segunda sentencia, se argumentó la anulación de los párrafos 1 y 2 del artículo 295 del Código de Procedimiento Penal, que no atentaría el derecho de defensa (Sentencia del 15 de enero de 1999).

En sentencia del 27 de junio de 2000, la Corte de Rusia hizo varias referencias a la jurisprudencia del Tribunal Europeo de defender el derecho de toda persona a beneficiarse de la asistencia de un abogado en la etapa preliminar en el proceso de justicia penal. El Tribunal Constitucional ruso primeramente se apoyó sobre la interpretación dada por la Corte Europa a la noción de «acusación» ${ }^{10}$. Enseguida se retomó palabra por palabra la formulación de la Corte Europea para concluir que «la denegación de asistencia de un abogado en las primeras horas de interrogatorio de la policía puede causar un daño irreparable a los derechos de la defensa, que no es compatible con los derechos del acusado en virtud del artículo 6.3 del $\mathrm{CEDH}_{\|}{ }^{11}$. Esto le permitió establecer el derecho del acusado a un abogado desde las primeras horas del interrogatorio.

También se invocaron los requisitos de las normas europeas de la justicia cuando la Corte Constitucional de Rusia ha defendido el principio de la doble instancia. En su sentencia de 12 de marzo de 2001, la Corte de Rusia adoptó la posición de la Corte Europea de Derechos Humanos ${ }^{12}$, al afirmar que «la existencia de un juicio justo conforme al artículo 6-1 de la CEDH se aplica sólo en la medida en que los derechos civiles de los solicitantes se ven afectados por la decisión judicial previa que puede ser impugnada y cuya legalidad pueda ser verificada por un tribunal». Esto tuvo un gran impacto debido a que el Tribunal Constitucional de Rusia ya había exigido la introducción de esta norma en el ámbito de procedimiento administrativo (Sentencia del 28 de mayo de 1999). El legislador introdujo el segundo tribunal, conforme a lo solicitado por el Tribunal Constitucional, pero en el procedimiento administrativo único. Así que tuvimos que esperar a una nueva pena de

10 Corte EDH Deweer v. Bélgica de 27 de febrero de 1980, Eckle v. Alemania el 5 de julio 1982 y Foti et al. Italia 10 de diciembre 1982 11 Quaranta v. Suiza, 24 de mayo 1991 Imbrioscia c. Suiza, 24 de noviembre de 1993, John Murray v. Reino Unido, de 8 de febrero de 1996.

12 TEDH Sentencia X c. Bélgica 10 de marzo de 1981. 
dos años después de la aplicación de las mismas medidas para el proceso penal.

En una sentencia dictada el 25 de enero de 2001, la Corte Constitucional de Rusia fue tan lejos como algunas disposiciones de la CEDH en la misma sentencia. Se han hecho disposiciones de las directrices CEDH para determinar el significado de la cuestión de la indemnización por parte del Estado por los daños causados por la acción o inacción de la justicia. De este modo, se ha adjudicado a la verdadera función de la CEDH «regulador de la ley», en palabras del abogado ruso Kanachevskij (2003) la jurisdicción superior llegó a dar más aclaraciones con respecto a la reparación de los diversos tipos de daños causados por el Estado en su sentencia de 19 de junio de 2002. De hecho, repitió palabra por palabra la posición de la Corte Europea de Derechos Humanos en Burdov vs. Rusia 07 de mayo 2001 a la conclusión de que el Estado no puede excusar la falta de recursos para no honrar sus deudas sobre la base de una decisión judicial. Miles de personas afectadas por las consecuencias del accidente nuclear de Chernobyl fueron capaces de confiar en esta jurisprudencia para hacer valer sus derechos después.

El sistema jurídico de Rusia por lo tanto se ha enriquecido un cuerpo de nuevas reglas de origen convencional y jurisprudencial. También continuó evolucionando después de la adopción de los nuevos códigos, como fue el caso de la Ley Federal de 30 de abril de 2010, sobre «compensación por la violación del derecho a ser juzgado dentro de un plazo razonable (Ley $\mathrm{N}^{\circ}$ 68-FZ), que era complementaria a los distintos códigos de procedimiento ${ }^{13}$, especificando la indemnización por las lesiones sufridas por una persona a causa de la violación del plazo razonable del procedimiento y la ausencia o retraso de la ejecución de las decisiones judiciales. Del mismo modo, la norma de la independencia judicial como base de la actividad de los órganos judiciales, en la Constitución de la Federación Rusa en los artículos 10, 120 a 122 y 124, se desarrolló en la legislación sobre el sistema los procedimientos judiciales y judiciales ${ }^{14}$. La última ley aprobada en el campo de fecha de 7 de febrero de 2011 y se centra en «los tribunales ordinarios de la Federación de Rusia» (Ley 1-CFL).

Esta influencia con toda seguridad, mantiene en algunas zonas las diferencias entre los principios del derecho de Europa y Rusia que pueden todavía ser identificados. Todavía existe hoy en día, por ejemplo, problemas de delimitación de competencias entre la jurisdicción ordinaria y los tribunales de arbitraje. Esto se aplica particularmente a los casos de relaciones de derecho público, la protección de los derechos intelectuales, etc. Del mismo modo, una serie de conflictos de competencia entre tribunales estatales y organismos no judiciales que regulan ciertos conflictos persisten en el sistema judicial ruso, lo que impide la correcta definición de un tribunal establecido por la ley.

\section{EL PLURALISMO JUSRISDICCIONAL}

\subsection{La distribución de competencias entre Las jurisdicciones}

El capítulo VII de la Constitución de la Federación rusa se dedica a la justicia. El artículo 118, que consta de tres párrafos, establece los principios básicos de la organización de la justicia en el país. Así, de acuerdo con los principios del Estado de Derecho, la Ley Fundamental establece que la justicia debe

13 Los artículos 2, 4.1, 6.1, 14.3 y 304. 2 del Código de Procedimiento Arbitral de la Federación de Rusia y en el artículo 6.1 del Código de Procedimiento Civil establece la obligación de hacer justicia y la aplicación de actos judiciales en un plazo razonable. Sección 4.1 del Código de Procedimiento Arbitral y el artículo 3.1 del Código de Procedimiento Civil de la Federación de Rusia se prevé la posibilidad de presentar una denuncia por incumplimiento de los plazos. Sección 27.1 del Código de Procedimiento Arbitral y el artículo 22.1 del Código de Procedimiento Civil prevé el establecimiento de un procedimiento de examen de estas quejas.

14 Los artículos 1.2, 5 y 33.1 de la Ley Constitucional Federal «en el sistema judicial de la Federación de Rusia»; los artículos 6 y 46.1 de la Ley Constitucional Federal «Los tribunales de arbitraje de la Federación de Rusia»; los artículos 9 y 10 de la Ley Constitucional Federal «Sobre el estatuto de los jueces de la Federación de Rusia»; los artículos 5, 9.3 y 167,3-5 Código Procesal Comercial; El artículo 8 del Código de Procedimiento Civil de la Federación Rusa. 
ser impartida únicamente por los tribunales (apartado 1), siendo prohibida la creación de tribunales de excepción (apartado 3). En segundo lugar, establece la división de poderes: "El Poder Judicial se ejerce por medio de procedimientos judiciales, del derecho civil, administrativo y penal» (apartado 2). Como se puede ver, el Tribunal Constitucional es parte del poder judicial y ninguna relación de jerarquía está establecida entre ellos y las dos jurisdicciones supremas rusas: la Corte Suprema de la Federación Rusa y la Corte Superior de Arbitraje la Federación de Rusia.

El Tribunal Constitucional es el único órgano competente para efectuar el control constitucional e interpretar la Constitución, el conjunto de tribunales del país puede someter sus casos a la corte constitucional. Sin embargo diferenciado su remisión. En virtud del artículo 125.2, sólo la Corte Suprema de la Federación Rusa y la Corte Superior de Arbitraje de la Federación de Rusia pueden demandar a la Corte Constitucional que se pronuncie sobre la conformidad a la Constitución: a) Las leyes federales, los actos normativos del Presidente de la Federación de Rusia, el Consejo de la Federación, la Duma del Estado, el Gobierno de la Federación de Rusia; b) de las Constituciones de las Repúblicas, los Estatutos, las leyes y demás actos normativos de los sujetos que la Federación Rusa adoptada en materia de competencia de los órganos del poder estatal de la Federación de Rusia y la jurisdicción conjunta del Estado de los órganos de poder de la Federación de Rusia y los órganos de poder de la misma federación; c) los acuerdos entre los órganos del poder estatal de la Federación de Rusia y los órganos del poder estatal de los sujetos de la Federación Rusa, los acuerdos entre los órganos del poder estatal de los sujetos de la Federación Rusa; d) tratados internacionales de la Federación de Rusia que no están en vigencia.
En lo que se refiere a los recursos concernientes a los derechos y libertades constitucionales, el artículo 125.4 abre la remisión a los tribunales para pedir a la Corte Constitucional verificar la constitucionalidad de la ley aplicada o aplicable en un caso particular según el procedimiento fijado por la ley Federal. El artículo 101 de la Ley Constitucional Federal «Sobre la Corte Constitucional de Rusia» (Ley 1-CFL), precisa que si bien se trata del conjunto de tribunales: «el Tribunal, cualquiera que sea el grado de la instancia en el curso del examen de un asunto, concluye que la ley aplicable en el caso no está de acuerdo con la Constitución de la Federación de Rusia, para hacer frente a la Corte Constitucional deberá enviar una solicitud de verificación de la constitucionalidad de esta ley». Desde el momento en que el tribunal toma la decisión de acudir a la Corte Constitucional, el proceso se suspende hasta la entrada en vigencia de la decisión del Alto Tribunal (artículo 103).

Si la distribución de competencias entre los tribunales parece obvia, no ha sido igual en el nivel de la puesta en práctica de las disposiciones constitucionales (Lazarev, 2000) ${ }^{15}$. La creación de la Corte Constitucional de Rusia se ha convertido en un factor de «desestabilización moral» porque implicó la reestructuración completa del sistema judicial soviético todavía en funcionamiento. Por otra parte, el poder judicial soviético era jerárquico en torno a la Corte Suprema de la URSS, que estaba equipado de tareas relativamente importantes. ${ }^{16}$ La creación de la Corte Constitucional ha sido entonces asimilada por la Corte Suprema como una competencia que atente con su supremacía (Morchtchakova, 1996), algunos de sus casos son sintomáticos de su deseo de erigir el actor que controla la constitucionalidad de las leyes ${ }^{17}$. Del mismo modo, en el auto de 31 de octubre de 1995 bajo el pretexto de querer dibujar reglas comunes para todos los tribunales a fin de la calidad de su trabajo -complicada por el contexto de la transición del orden jurídico- la Corte

15 Algunos representantes de la doctrina fueron muy críticos de las disposiciones relativas a la distribución de competencias entre los tribunales, mientras que los problemas de su aplicación se han producido a causa de su insuficiencia, o incluso contradictorias. 16 Ella estaba hablando no sólo como un foro sentencias de casación de los tribunales ordinarios, sino también como un tribunal de primera instancia.

17 Véase en particular el caso de la región de Yaroslavl 05 de julio 1995 y el caso de Irkutsk el 21 de septiembre de 1995. 
Suprema ha dirigido una serie de instrucciones a los tribunales de derecho común que llevan a repensar la relación entre los tribunales ordinarios y el Tribunal Constitucional18. Esto reforzó la autonomía de los tribunales ordinarios, que obtuvieron no solo el poder de descartar las leyes que les parecían inconstitucionales, sino también su monopolio: la Corte Suprema se comprometió también a casar las sentencias de los tribunales inferiores cuando ellos no hubieran descartado una ley inconstitucional.

A su vez, la Corte Constitucional reaccionó y estableció el principio de su monopolio en materia de control de constitucionalidad de las leyes. Ella recordó a los tribunales ordinarios su obligación de acudir a ellos en los casos en los que fueron confrontadas normas inconstitucionales ${ }^{19}$. Para justificar su competencia exclusiva, la Corte Constitucional comenzó a implementar una interpretación sistémica de la Constitución de Rusia. Para los jueces constitucionales, los artículos 125, 126 y 127 de la Constitución reparten entre las distintas jurisdicciones las tareas previstas en el artículo 118 línea 2 de la Constitución. El análisis de estas diversas disposiciones muestra que ella no ha atribuido la competencia en materia de control de constitucional de los actos enumerados en el artículo 125 si no a la Corte Constitucional. La alta instancia apoyó su argumento en una segunda norma de referencia: el artículo 6 del Convenio Europeo de Derechos Humanos sobre el derecho a un proceso equitativo. Según el Tribunal, se desprende de un principio general de justicia que el tribunal competente para considerar un caso es el que se crea y opera sobre la base de la ley. Por lo tanto, sólo la Constitución y la ley pueden determinar el órgano competente para la revisión constitucional.

En su decisión de 16 de junio de 1998, el Tribunal Constitucional ha reiterado su posición y, en una decisión publicada dos años más tarde, ha añadido que la diferencia fundamental entre el control ejercido por el Tribunal Constitucional y los tribunales ordinarios está en la norma de referencia y los efectos de las decisiones: un efecto erga omnes para esas decisiones e inter partes para aquellas decisiones dictadas por los tribunales de derecho común (Decisión de 11 de abril de 2000).

Las «disputas» de los jueces han cesado en la medida de la reforma del sistema judicial y el aprendizaje progresivo del respeto de la letra de la Constitución.

\subsection{La Corte Constitucional Federal}

El Estado de Derecho exige un juez constitucional, como se exige un juez de legalidad. Sin embargo, no se requiere que los beneficiarios individuales de las normas del sistema pueden dirigirse directamente al juez de constitucionalidad, cada país tendrá la libertad para nombrar a los titulares de ese derecho. La Federación de Rusia fue el primero entre los países post-soviéticos en introducir, desde el principio, la aplicación individual. El texto constitucional contiene nociones muy generales sobre la situación de las personas que disfrutan de este derecho. De conformidad con el artículo 125 (4) de la Constitución, cualquier ciudadano puede acudir a la jurisdicción constitucional. Debido a su amplia formulación, varias preguntas surgieron con respecto a los beneficiarios del derecho de acceso a la justicia.

\footnotetext{
18 Esto incluyó una invitación a no dirigirse al Tribunal Constitucional si las disposiciones de la norma constitucional no requieren de una regulación adicional y no se menciona la necesidad de adoptar una ley federal sobre los derechos, las libertades y deberes del hombre y del ciudadano; cuando el tribunal estaba convencido de que la ley federal aprobada después de la entrada en vigor de la Constitución estaba en conflicto con sus disposiciones; cuando la ley u otro acto jurídico adoptado por un sujeto de la Federación de Rusia en un área de jurisdicción conjunta era contraria a la Constitución de la Federación Rusa y la ley federal, que debía regir la relación jurídica en cuestión estaba ausente; cuando el tribunal llegó a la conclusión de que la ley federal aprobada antes de la Constitución estaba en su contra. La justificación de esta posición de la Corte Suprema se basó en dos argumentos: el principio constitucional del efecto directo de la Constitución (los tribunales están autorizados por la propia Constitución, en el artículo 15, para aplicar directamente las disposiciones constitucionales) y la fundamentalidad de derechos a ser protegidos (los tribunales ordinarios tienen la misión principal es defender los derechos y libertades fundamentales).

19 Decisión de 3 de mayo de 1995, sobre la verificación de la constitucionalidad del artículo 220 (1) y 220 (2) del Código de Procedimiento Penal de la RSFSR, previa notificación del ciudadano V. Avetian.
} 
La primera pregunta fue si sólo los ciudadanos tienen el derecho de acudir directamente a la Corte Constitucional en el marco del control concreto de las leyes o si los extranjeros y los apátridas son, también, titulares de este derecho cuando sienten que sus derechos constitucionales han sido violados. En el marco de los debates doctrinales, ambas partes son opuestas. Los defensores de una visión estrecha de la ciudadanía argumentaron que este derecho podría ser reconocido sólo a los ciudadanos de Rusia, como es requerido por la Ley Fundamental (Lazarev, 2000). Para otros, se infiere de lo dispuesto en el artículo 62 § 3 de la Constitución de una visión más amplia del concepto de que, además de los ciudadanos, en sentido estricto, también debía incluir los extranjeros y los apátridas (Alekseev, 1998). Por su parte, la Corte Constitucional de Rusia ha unido las posiciones del segundo campo. En 1998, ella aceptó estudiar una acción emanada de un apátrida ${ }^{20}$. En su sentencia, la alta jurisdicción señaló que «se desprende de lo dispuesto en los artículos 46, 17, § 2, 62 § 3 y 125 § 4 de la Constitución de la Federación de Rusia la oportunidad de defender sus derechos y libertades, por medio de la justicia constitucional debe garantizarse a todos, es decir, también a los ciudadanos extranjeros y los apátridas, si una ley viola sus derechos y libertades garantizados por la Constitución». Ella apoyó su argumentación en los artículos 22 y 46 de la Constitución, que contienen expresiones neutrales tales como "cada uno» y "ninguno puede» - para garantizar a todas las personas protección judicial, independientemente de que se detente o no la ciudadanía de la Federación de Rusia (Sentencia del 17 de febrero 1998).

La segunda cuestión que se plantea se refería al derecho de acudir a la jurisdicción de las personas jurídicas. Como hemos visto, la Constitución habla de «ciudadanos» solamente. El artículo 96.1 de la Ley Constitucional Federal «Sobre la Corte Constitucional de la Federación rusa», afirma que la denuncia puede ser individual o colectiva; puede venir de una asociación de ciudadanos, así como de otras entidades y particulares. Por lo tanto, era si el derecho de recurso debe extenderse a las dos asociaciones con fines de lucro y organizaciones sin fines de lucro, asociaciones nacionales como los internacionales. En su sentencia de 24 de octubre de 1996, el Tribunal Constitucional de la Federación de Rusia dispuso que «el derecho de acudir a la jurisdicción está abierto a cualquier persona jurídica, independientemente de su forma de organización económica»; puede ejercerse «individual o colectivamente, de diversas sociedades» (Decisión de 9 de noviembre de 2010). En 1999, al igual que los individuos, el alto Tribunal Constitucional de Rusia amplió el derecho de recurso a las personas jurídicas extranjeras que tengan su sede en el territorio de la Federación Rusa (Sentencia del de 14 de mayo de 1999). ${ }^{21}$

En sus decisiones, la Corte Constitucional de Rusia ha demostrado una abertura que encuentra focos paralelos en el derecho comparado. La evolución constante del número de demandas individuales permite afirmar sin exageración que el recurso constitucional contribuye más que cualquier otro tipo de procedimiento, al fortalecimiento de su reputación como garante de los derechos y libertades.

\subsection{Las Cortes Constitucionales / Estatutarias Federadas}

La Constitución rusa reconoce a los sujetos de la Federación el derecho a establecer su propio

20 En este caso, el apátrida Jah'ja Dasti Gafur, que se alojaba en Rusia, fue detenido por orden del fiscal de la ciudad de Moscú, sobre la base de las decisiones de expulsión con escolta OVIR de la ciudad de Moscú. Estuvo detenido durante más de dos meses en el centro de rehabilitación social número 1 de la Ciudad de Moscú y el 29 de abril de 1997, fue expulsado en Suiza. Se adoptó la decisión de expulsión Jah'ja Dasti Gafur sobre la base del artículo 31 § 2 de la Ley de la URSS «Sobre la situación jurídica de los ciudadanos extranjeros en Rusia», según la cual los ciudadanos extranjeros y personas sin ciudadanía se vieron obligados a abandonar el país en el plazo fijado por la decisión de expulsión. El artículo añade que cualquier persona que se niega a salir dentro de ese período sería detenido por orden de la Fiscalía y la fuerza a quitar, y que la detención durará el tiempo necesario para la expulsión. Ahora bien, según la demandante, el arresto y la detención del ciudadano extranjero o apátrida, según lo dispuesto en esta ley violaba el derecho constitucional de toda persona a la libertad y a la inviolabilidad y eran, por tanto, contrario al artículo 22 de la Constitución.

21 Sobre la verificación de la constitucionalidad de los artículos $131 \S 1$ y $308 \S 1$ del Código de Aduanas de la RF. 
sistema de los órganos de poder del Estado (artículo 77) y establecer la regulación legal de su actividad (artículo 76). Como se ha señalado por algunos representantes de la doctrina en el contexto de un auténtico federalismo, la división de poderes entre el gobierno federal y las comunidades federadas también significa el establecimiento de una revisión constitucional a nivel federal (Morchtchakova, 1998). Por lo tanto, en la aplicación de los principios constitucionales del federalismo en su constitución o estatuto, treinta y dos entidades federadas han previsto la creación de una jurisdicción constitucional para garantizar la supremacía del texto constitucional en su territorio.

La Ley Constitucional Federal «Sobre el Sistema Judicial de la Federación Rusa» del 31 de diciembre 1996 (Ley N 1-FKZ), llegó a pedir a los principios generales de la organización de la justicia constitucional en el ámbito estatal. De acuerdo con el artículo 4, apartado 2, de la Ley, las jurisdicciones constitucionales federadas son jurisdicciones que relevan de la competencia de cada uno de los sujetos de la Federación, pero ellas hacen parte del sistema judicial de la Federación de Rusia, que también asume la garantía, la independencia e imparcialidad de los jueces constitucionales, previsto en la ley federal «Sobre el Estatuto de los Jueces de la Federación de Rusia del 26 de junio 1992» (Ley No. 3132-1). La creación y organización de la actividad de los tribunales constitucionales federados deben realizarse bajo las leyes de los sujetos de la Federación Rusa, que, a su vez, deben cumplir con la ley federal.

El artículo 27 de la ley federal luego viene con otros detalles importantes. Proporciona, en el apartado 1, que los tribunales constitucionales federados ejercerán dos funciones principales: dar la interpretación oficial de la Constitución o el Estatuto de la entidad federativa y el ejercicio de constitucionalidad de las leyes federadas y todos los actos normativos expedidos por las autoridades de las entidades federativas. El apartado 2 del mismo artículo establece la obligación de cada uno de los temas acordados para establecer un tribunal constitucional que apoye su financiamiento, que serán deducidos del presupuesto de la entidad federal. Esta restricción presupuestaria tal vez podría explicar el lento proceso de la creación de tribunales constitucionales federados. En el año 2002, sólo catorce de las treinta y dos entidades han previsto el establecimiento de tal jurisdicción en su texto fundamental que van hasta el final de su procedimiento. El 1 de enero de 2014, la cifra de los sujetos que prevé un control judicial asciende a cincuenta y cuatro. Sin embargo, diecisiete entidades federales disponen de una jurisdicción especial: trece Cortes Constitucionales creados por las repúblicas federadas y cuatro Cortes Estatutarias creadas por tres provincias y la ciudad de San Petersburgo.

Esto plantea dos problemas principales. En primer lugar, en los asuntos que no disponen de una jurisdicción constitucional, las violaciones de los derechos y libertades permiten, ciertos actos que son competencia exclusiva de las autoridades estatales que no están sujetos a ningún control. En segundo lugar, en la defensa de los derechos y libertades, algunos ciudadanos de la Federación de Rusia son más privilegiados que otros: aquellos sujetos que habiendo creado un jurisdicción constitucional pueden defender sus derechos cuando consideren que se han violado o limitado a manera infundada, mientras que los que residen en una entidad federada no ha establecido un control jurisdiccional ni podrán hacerlo. Por lo tanto, el principio de igualdad garantizado por la Constitución de Rusia no se respeta plenamente.

Otro punto importante, establecido en el apartado 4 del artículo 27 de la Ley del 31 de diciembre de 1996 sobre la autoridad de las decisiones de los tribunales constitucionales federadas. Tienen un efecto erga omnes y no pueden ser apeladas. Por lo tanto, no existe una relación jerárquica entre el Tribunal Constitucional Federal y los tribunales constitucionales federados. Estos últimos tienen plena independencia en el ejercicio de sus funciones. Esto no quiere decir que no hay colaboración entre las jurisdicciones Constitucional Federal y las jurisdicciones constitucionales federadas. Como subrayó el ex presidente de la Corte Constitucional de la República de Komi, Y. Gavrioushov, lo jueces constitucionales federados «están destinados a fortalecer 
la unidad del espacio jurídico ruso» (Zadiora, 2002). Y el juez de la Corte Constitucional de la República de Saka Sr. Filipov, agregó que «la colaboración de los órganos judiciales es la clave para la construcción de un conjunto coherente de normas legales» (Danelciuc, 2012). Incluso si las jurisdicciones constitucionales federadas no han acudido continuamente a la Corte Constitucional Federal, los principios jurisprudenciales establecidos por la alta jurisdicción Federal son a menudo retomados en la jurisprudencia de las cortes federadas.

Inicialmente consideradas por las autoridades federales como «las armas en manos de los políticos ambiciosos» (Gadjiev \& Kriajkov, 1993), los jueces constitucionales, federales y federados, finalmente encontraron un equilibrio. El diálogo entre los jueces se construye poco a poco. Esta colaboración sin duda lleva una complementariedad dinámica en la protección de los derechos y libertades, pero también es necesario que todos los sujetos federados finalmente establezcan su propia institución de control jurisdiccional para ser eficaz y eficiente en todo el territorio del Estado ruso.

\section{PLURALISMO DE LAS JURISDICCIONES $Y$ PLURALISMO DE LA JURISPRUDENCIA}

\subsection{Las medidas adoptadas para evitar discrepancias}

Las constituciones de URSS no contenían disposiciones relativas a la relación entre el derecho internacional y el derecho nacional y de aplicación del derecho internacional por los tribunales. Pero la decisión de la Asamblea Plenaria (Plenum) de la Corte Suprema de la URSS de 11 de abril 1969 «Sobre la cuestión de la aplicación de las leyes por las jurisdicciones en el momento del examen de los que resulten del trasporte de mercancías o de equipaje» da fe de la existencia de prácticas en este ámbito (Esakov; Melin y Mask- 2011), incluso si eran raros y tuvieran un carácter circunscrito. Por tanto, en la § 14 de la decisión, la Corte Suprema indicó que: «Las jurisdicciones debían tener en cuenta que si un acuerdo internacional de la URSS prevén otras reglas del el derecho civil o procesal civil soviético, reglas de acuerdo internacional que se aplican en el momento de las diferencias resultantes de los acuerdos sobre el transporte internacional».

De hecho, como lo señalaba Blatova (1987), la implementación de los acuerdos internacionales se hizo en una de dos formas: la aplicación «compleja» o aplicación «prioritaria». En el primer caso, la norma internacional se aplicó junto con una disposición nacional. En el segundo, la norma internacional se sustituía por una disposición nacional, en caso de conflicto de normas. En ambos casos, el derecho internacional no podía aplicarse si no en las situaciones explícitamente previstas por una legislación soviética diseñado ad hoc.

La Constitución de la Federación Rusa en 1993 tenía la intención de abrir el derecho internacional. Se establece en su artículo $15 \S 4$ que:

Los principios y normas universalmente reconocidas y los tratados internacionales de la Federación de Rusia son parte integrante de su sistema jurídico. Si otras reglas que aquellas previstas por la ley son establecidas mediante un tratado internacional de la Federación de Rusia, se aplicarán las normas del tratado internacional.

Las disposiciones de este artículo han sido desarrolladas por la Ley federal N ${ }^{0} 101-F Z$, de 16 de julio 1995 «tratados Internacionales de la Federación de Rusia». Por lo tanto, en virtud del artículo 5 § 3 de la Ley, «Las disposiciones de los acuerdos internacionales de la Federación de Rusia publicadas oficialmente y cuya aplicación no requiere la adopción de leyes nacionales tienen un efecto directo en la Federación Rusa» (Vitruk, 2002:1011). En el mismo tiempo ningún procedimiento particular de la puesta en obra de estas normas, ni de la jurisprudencia de las decisiones internacionales ha sido previsto desde el inicio. Por el hecho de que la jurisprudencia no ha hecho parte tradicionalmente de las fuentes de derecho ruso, han aparecido interrogantes en cuanto al efecto de las jurisprudencias de las jurisdicciones internacionales y europeas, sobre todo porque las leyes federales no proporcionan ninguna especificación en la materia. Su aclaración era importante porque era necesario garantizar la aplicación eficaz de los compromisos internacionales 
adquiridos por la Federación de Rusia. Los jueces rusos están mal entrenados y prácticamente no tienen experiencia en la materia, un trabajo de fondo debía estar hecho con el fin de evitar las interpretaciones contradictorias y poner en marcha un sistema eficaz de protección de los derechos y libertades.

Estas cuestiones han dividido la doctrina, al igual que los miembros de la Corte Constitucional de Rusia. En cuanto a la jurisprudencia del Tribunal de Derechos Humanos, en particular, según el juez Nikolai Vitruk, «el hecho de que el sistema jurídico de Rusia no reconoce el carácter obligatorio de los precedentes y la formación de derecho por aquellos, la jurisprudencia de la Corte Europea no se puede utilizar como fuentes de derecho en la Federación Rusa». De acuerdo al juez Gadis Gadzhiev, las sentencias de la Corte Europea constituyen precedentes que son aplicadas por el Tribunal Constitucional y que se deben aplicar por todos los tribunales ordinarios. La posición del Presidente de la Corte Constitucional, Valery Zorkin, está inscrita en la misma línea. En su opinión, como es el caso de la CEDH, las sentencias del Tribunal Europeo deben también ser considerados como fuentes del derecho.

Agrega, además, que de acuerdo con el principio de precedencia establecido en el artículo 15 de la Constitución, el CEDH debe ser respetado por todos los actores involucrados en la implementación de la ley. Todas las jurisdicciones creadas sobre el territorio de la Federación Rusa y la obligación de tener en cuenta la jurisprudencia de la Corte Europea al igual que la Corte Constitucional Federal.

En dos decisiones importantes, la Corte Constitucional de Rusia reiteró las posiciones expresadas por los dos jueces. Así, en su sentencia de 25 de enero de 2001, ella emitió su opinión con respecto al lugar de la CEDH y la jurisprudencia de la TEDH en el sistema jurídico de Rusia, al establecer que son «partes integrantes del sistema jurídico Ruso y debe prevalecer sobre las leyes y la jurisprudencia federal y regionales contrarias» (Sentencia de 25 de enero de 2001, N ${ }^{\circ}$ I-P). En su sentencia del 5 de febrero de 2007, cuando la alta jurisdicción se pronunció sobre el efecto de la CEDH y de las sentencias de la Corte de Derechos Humanos, ella afirmó que por el hecho de que el CEDH y las sentencias del Tribunal Europeo de los derechos humanos son parte del sistema jurídico ruso, deben por lo tanto ser considerados por el legislador federal para regular las relaciones sociales los órganos de aplicación del derecho encargados de hacer cumplir la ley para aplicar las normas pertinentes.

En sentencia del 26 de febrero de 2010, la Corte Constitucional de Rusia se pronunció de nuevo en el tema de la aplicación de las decisiones de la Corte EDH. Ella constató la presencia de un vacío jurídico en el Código de Procedimiento Civil de la Federación de Rusia, que no hizo mención del procedimiento que debía ser aplicado en el caso de la condena del Estado ruso por violación de la Convención. Tras esta decisión, un proyecto de revisión del Código de Procedimiento Civil se presentó a la Duma el 15 de julio de 2010. La reforma entró en vigor el 1 de enero de 2012. En su nueva forma, el artículo 392 del Código de Procedimiento Civil de la Federación de Rusia prevé, específicamente en el párrafo 4, Parte 4, «la constatación hecha por la Corte EDH de una violación de la Convención constituye el fundamento para reexaminar el asunto sobre nuevas cargas» (Sultanov, 2010).

Por su parte, las dos Cortes Supremas rusas han tomado también medidas para reducir el riesgo de transmisión de diferentes interpretaciones. En una sentencia de 31 de octubre de 1995, dada en Asamblea Plena, la Corte Suprema de Justicia de la Federación de Rusia dispuso que los tribunales ordinarios no debieran hacer cumplir una ley que establecería reglas diferentes a las de un tratado internacional que entró en vigor (Sentencia del 31 de octubre de 1995). Ella vino con otras precisiones en la materia en su sentencia del 10 de octubre 2003, «Sobre la aplicación por las jurisdicciones del derecho común de los principios y normas generalmente admitidas por el derecho internacional y los acuerdos internacionales de la Federación de Rusia». Ella inicialmente fijo las normas generales del derecho internacional. Por lo tanto, los acuerdos internacionales deben ser 
aplicados por las jurisdicciones rusas si Rusia es una de las partes, si han entrado en vigor y se han publicado oficialmente, y si lo son, por naturaleza, de aplicación directa. Las jurisdicciones rusas también tienen el derecho de interpretar las disposiciones de los acuerdos internacionales que aplican, con base en las reglas generales de interpretación, según la definición de la Convención de Viena «Por el Derecho de los Tratados» de 23 de mayo 1969. Esta sentencia también contiene información importante sobre el lugar de la CEDH y la jurisprudencia de la Corte EDH en el sistema jurídico ruso (Sentencia de la Corte Suprema del 10 de octubre de 2003). La Corte Suprema reconoció por primera vez la autoridad de la Corte de Estrasburgo, al establecer que:

Como miembro de la Convención de salvaguarda de los derechos del hombre y de las Libertades individuales, la Federación de Rusia reconoce el carácter obligatorio de la jurisdicción de la Corte $E D H$, en relación con la interpretación y aplicación de la Convención y sus Protocolos en el caso de una presunta violación por parte de la Federación Rusa.

Por lo tanto, la aplicación por los Tribunales de la Convención debe hacerse a la luz de la jurisprudencia del Corte EDH con el fin de evitar la violación de la CEDH (Bjuleten, 2003). Además, si, al revisar un caso, un tribunal identifica las circunstancias que condujeron a la violación de los derechos y libertades garantizados por la Convención, debe informar a los órganos y funcionarios pertinentes y exigir la adopción de medidas adecuada para poner fin a las violaciones.

El Decreto de la Asamblea Plena de la Corte Suprema Federal del 27 de junio 2013 sobre la aplicación por los tribunales de derecho común de la convención de salvaguarda de los derechos del hombre y de las libertades individuales, también discute varios puntos importantes. En primer lugar, el Tribunal señala que la salvaguarda de los derechos y libertades del hombre garantizados por la Convención incumbe a todos los órganos del Estado, incluidos los tribunales. En segundo lugar, con el fin de poner fin al debate sobre la aplicación por los tribunales ordinarios de las posiciones jurídicas de la Corte EDH, identifica y explica dos casos. En cuanto a las posiciones jurídicas contenidas en la sentencia del Corte de Estrasburgo, dictadas con respecto a la Federación de Rusia, ellas son obligatorias para los tribunales ${ }^{22}$. En lo que respecta las sentencias proferidas contra los demás Estados miembros de la Convención, las posiciones jurídicas de la Corte EDH deben ser tomados en cuenta por los tribunales rusos si las circunstancias del caso son similares. La Corte Suprema también ha indicado a los jueces ordinarios a prestar especial atención a las causas de la limitación de los derechos y libertades. Recordó los criterios señalados por la Corte de Estrasburgo que deben tenerse en cuenta: la posibilidad de limitación únicamente por la ley, la existencia de una finalidad legítima y si la limitación se torna como indispensable en una sociedad democrática (con el respeto del principio de proporcionalidad).

Además de su importancia práctica, la originalidad de este Decreto radica en la forma en que se la Corte Suprema preparó por primera vez un proyecto de decreto, en la primavera de 2013, y lo remitió a la justicia ordinaria y las instituciones de investigación y educación superior para el debate. Para el proyecto final del decreto, se tuvo en cuenta las observaciones y propuestas formuladas por los distintos actores, profesionales y representantes de la doctrina. Este nuevo método de trabajo de la Corte Suprema demuestra su disposición a entablar un diálogo para llegar a un consenso y poner fin a las diferencias de interpretación que dificultan el establecimiento de un orden común de garantía y protección de los derechos y libertades.

22 En este punto, hace suya la posición de una gran parte de la doctrina rusa que afirma desde hace años, que la autoridad del TEDH juega tanto para sentencias «declarativa» en el que una violación se encuentra o no la violación de la Convención, en cuanto a los llamados juicios de «beneficio» en el que se da «satisfacción justa» para el solicitante. 


\subsection{La aparición de tensiones entre los jueces y su resolución}

Desde la ratificación por la Federación de Rusia con la $\mathrm{CEDH}^{23}$, las relaciones entre los jueces nacionales y jueces europeos estaban muy apaciguados, incluso mostrando un grado de complicidad. Sabemos que antes de decidir sobre una presunta violación, la Corte de Estrasburgo procede a un análisis de las peculiaridades de las normas constitucionales del Estado defensor de su legislación y las decisiones judiciales, incluidas las decisiones de las jurisdicciones Constitucionales. En varias ocasiones, la Corte EDH ha dado una evaluación positiva de la jurisprudencia de los jueces constitucionales rusos, resaltando el carácter serio y convincente de las decisiones proferidas. En Sakhnovski vs. Rusia (sentencia del 02 de noviembre de 2010), por ejemplo, la Corte de Estrasburgo en la búsqueda de una violación del artículo 6 § 1 y $\S 3$ del CEDH, hizo hincapié en que la Corte Constitucional de Rusia había votado siete veces sobre el respeto del derecho de toda persona a la asistencia jurídica calificada.

De este modo, los jueces europeos no sólo han sancionado el Estado ruso debido a los problemas actuales de la defensa, también señalaron el incumplimiento por parte del legislador de las decisiones de la Corte Constitucional. Del mismo modo, en la sentencia Burdov vs. Rusia (04 de septiembre 2002), la Corte de Estrasburgo ha encontrado una violación del artículo 6 § 1 de la Convención por el Estado ruso, debido a la no ejecución de las decisiones judiciales a favor del solicitante. Al hacer el análisis del sistema jurídico de Rusia, la Corte de Estrasburgo destacó que, en su sentencia del 25 de enero de 2001, el Tribunal Constitucional de Rusia se pronunció sobre la responsabilidad del Estado por daños y perjuicios causado en el marco de la administración justicia y, en relación con el artículo 6 de la Convención, que ella había concluido con la obligación para el parlamento de legislar con el fin de fijar las condiciones y el procedimiento de reparación por parte del Estado por los daños causados por la acción u omisión indebida de un tribunal o un juez y determinar cuál tribunal es competente «ratione material» $\mathrm{y}$ «ratione loci» para conocer de estas causas.

Luego, en la sentencia Partido Conservador de Empresarios y Otros vs. Rusia (sentencia del 11 de abril 2007), La Corte EDH concluyó con la violación del artículo 3 del Protocolo número 1 de la Convención, dejó en claro que su opinión era la misma que la de la Corte Constitucional de Rusia. El juez europeo incluso dijo que no veía ninguna razón para apartarse de las conclusiones de la Corte rusa. En su opinión, el Tribunal Constitucional ha establecido de manera convincente que la descalificación de los candidatos y alianzas electorales enteras por razones no relacionadas con su conducta había infringido injustificadamente su derecho de voto pasivo, independientemente de las razones para la renuncia de uno de los tres primeros candidatos, y contrario al principio nulla poena sine culpa.

El caso Markin vs. Rusia del 07 de octubre 2010 marcó un giro real en la relación entre los jueces de Estrasburgo y la Corte Constitucional de Rusia. Por primera vez desde la ratificación de la Federación de Rusia ante la CEDH, La Corte de Estrasburgo ha sido muy crítica frente a la Corte Constitucional constatando la violación de los artículos 8 y 14 del CEDH, ella señaló que el argumento central de la Corte Constitucional de Rusia en su decisión del 11 de agosto 2008 no fue convincente. En efecto, los jueces constitucionales rusos habían concluido la compatibilidad con el artículo 19 de la Constitución de las disposiciones de la ley atacada por el demandante que le prohibían a los militares de sexo masculino beneficiarse de una licencia por paternidad. Ellos invocan como fundamento los requisitos específicos de servicio en las fuerzas armadas que fueron impuestas para garantizar la seguridad de defensa y el Estado.

23 Ley Federal «Sobre la ratificación del Convenio Europeo para la Protección de los Derechos Humanos y libertades Fundamentales» de 30 de marzo de 1998. 
Según la Corte de Derechos Humanos, la decisión de la Corte Constitucional de Rusia se basa en meras conjeturas, sin tratar de verificar la realidad apoyándose sobre bases estadísticos o poniendo en balance los intereses contradictorios del mantenimiento de la eficacia operacional de la armada, de un lado, y del deseo de proteger a los militares del sexo masculino contra la discriminación en su vida familiar y para satisfacer mejor las necesidades de sus hijos, por el otro. La Corte de Estrasburgo consideró que los argumentos de la Corte Constitucional de Rusia se basan en la concepción del papel tradicional de los dos sexos que ve en la mujer la que se ocupa de los niños u en el hombre aquel que prevé las necesidades de la familia. La Corte de Estrasburgo fue particularmente golpeada por el argumento de la Corte Constitucional según la cual los militares del sexo masculino tienen la posibilidad de renunciar a la armada cuando ellos lo deseen ocuparse de sus hijos. Ellos se ven entonces impuestos a una elección difícil, sobre todo porque el carácter singular de las fuerzas armadas consiste en la dificultad de trasplantar en la vida civil las cualificaciones y una experiencia esencialmente militar.

Como era de esperarse, de esta decisión se ha escrito mucho en la Federación Rusa. Primeramente el antiguo juez ruso en los TEDH, Anatoly Kovler, presentó su descuerdo en una opinión disidente anexa a la decisión. En su opinión, dadas las circunstancias particulares del caso y el amplio margen de apreciación reconocida a los Estados para todo lo relacionado con la seguridad nacional, los argumentos de la Corte Constitucional son justificados y objetivos. A continuación, señaló que el reconocimiento excepcional como el permiso parental para las mujeres es una opción política que se explica por el papel social especial que juegan estas últimas en tanto que madres. En opinión del juez de Rusia, la política del Estado ruso en esta área está plenamente justificada ante los retos demográficos que comienzan a ser confrontados. El juez Kovler luego señaló de manera aguda con conocimiento directo de su sociedad y sus necesidades, las autoridades nacionales se encuentran en principio mejor ubicadas que el juez internacional para determinar que es de utilidad pública y que no lo es. En caso parecido la Corte EDEH respeta generalmente las decisiones políticas de los legisladores nacionales, a menos que haya un «fundamento, manifiestamente irrazonable» (Caso -Dickson vs. Reino Unido, 04 de diciembre 2007). Sin embargo en este caso no lo era.

A nivel nacional, el Presidente de la Corte Constitucional de Rusia Valery Zorkin, lamentó la posición del Tribunal de Estrasburgo, sostiene que el juicio era un «factor de debilitamiento de la corte nacional». La Doctrina de Rusia, ha calificado de «duro e injusto» los propósitos de la Corte EDH frente a la decisión del juez Constitucional. En opinión de algunos expertos, debido a su posición, el Tribunal de Estrasburgo creó un conflicto en el sistema jurídico de Rusia, mientras se hacen esfuerzos durante años para construir un sistema jurídico coherente. Propusieron optar por la solución adoptada por el Tribunal Constitucional de Alemania que en octubre de 2004, habían enfrentado la misma situación como consecuencia de la decisión de Estrasburgo de 26 de febrero de 2004. La alta corte alemana concluyó que el legislador tenía el derecho, en casos excepcionales, a no tener en cuenta el derecho de los tratados internacionales cuando esta era la única manera de preservar la soberanía del Estado y de los principios constitucionales fundamentales.

Un grupo de parlamentarios rusos se acercó con una propuesta aún más radical. Dos proyectos de ley fueron presentados a la Duma del Estado, dispone que las decisiones de los órganos interestatales se realizarán en el futuro si la Corte Constitucional reconoce que esas decisiones no violan la Constitución de la Federación Rusa. Ambos proyectos fueron abandonados después de una primera lectura.

Para desbloquear la situación, se hicieron concesiones de ambas partes. En primer lugar, el 22 de marzo del 2012, en la sentencia Konstantin Markin vs. Rusia proferida por la sala plena, la Corte Europea de Derechos del Hombre, mientras qua ha tenido reposiciones más atemperados frente a la Corte Constitucional rusa. A su vez, en la decisión de 6 de diciembre de 2013, el Tribunal Constitucional de la 
Federación de Rusia expresó, por primera vez, sus puntos de vista sobre cómo las sentencias del Tribunal Europeo de Derechos Humanos debe aplicarse en Rusia si entran en conflicto con la jurisprudencia de la Corte Constitucional. El Tribunal se ha abstenido cuidadosamente de establecer principios generales o proclamar su superioridad frente a la Corte EDH. Ella optó por una solución de los conflictos en cada caso. ${ }^{24} \mathrm{Al}$ hacerlo, la alta jurisdicción rusa ha demostrado sabiduría porque, como lo afirmaba el presidente Genevois en la década de 1980, «la negativa de diálogo, lejos de ser un signo de fortaleza, seria por el contrario una admisión de debilidad» (Delmas-Marty, 2008).

Este caso no constituye el único ejemplo demostrando que el dialogo de los jueces «no es exclusivo de los conflictos y la competencia» (Delmas-Marty, 2008). En varias ocasiones, ya sea Rusia o en otras partes de los Estados, se ha observado que un diálogo es, sobre todo, un cambio de puntos de vista. Induce tanto el acuerdo y concordia que la oposición, contradicción o incluso discordia. Mientras tanto, el profesor Andriantsimbazovina (2009) considera las diferencias de opinión no pueden ser obstáculos 0 fuentes de bloqueo del sistema de garantías. En cambio, podrían ser vectores de intercambios que favorezcan la consecución de un perfeccionamiento bien visto por el derecho. Esperemos que esto va a ser el caso pues «la historia de los derechos humanos no es la historia de una marcha triunfal ni la historia de una causa perdida: es la historia de un combate», según lo afirma la profesora Lochak (2002).

\section{CONCLUSIONES}

El nuevo sistema político se basó en el respeto de los derechos y las libertades, lo cual se dio dado que los redactores de la constitución tuvieron en cuenta tres pasos importantes: i). La redacción del catálogo de derechos y libertades conforme a estándares internacionales; ii). La introducción de nuevas medidas de seguridad en pro de fortalecer los estados institucionales, federales y federados, para la protección y promoción de los derechos humanos y prevenir su violación, y; iii). La apertura del Estado ruso a la justicia internacional.

De esta manera, la constitución rusa define tres ideas dominantes para el desarrollo del respeto a los derechos y libertades de sus ciudadanos: i) la dignidad humana, ii) la libertad y iii) la igualdad. Además, contiene los llamados derechos de tercera generación, los cuales establecen el derecho de toda persona a un medio ambiente favorable, información fiable sobre su estado y para reparar el daño a su salud o la propiedad por delito ecológico. Sin embargo, la Constitución de 1993 establece varios niveles de protección.

Una situación particular de limitación de derechos fundamentales tiene lugar cuando las medidas de emergencia son introducidas, es decir, cuando en el Estado aparece en situación amenaza excepcional cuya resolución requiere el uso de medios especiales. El control estricto de estos límites se encuentra dentro de la jurisdicción de la Corte Constitucional, que debe garantizar el respeto de los principios de proporcionalidad y oportunidad.

En Rusia, los jueces constitucionales han tenido un papel muy importante durante el proceso de reforma del sistema normativo, canalizando el trabajo del legislador y armonizándolo para que cumpla con los estándares europeos. También se invocaron los requisitos de las normas europeas de la justicia cuando la Corte Constitucional de Rusia ha defendido el principio de la doble jurisdicción.

Así, de acuerdo con los principios del Estado de Derecho, la Ley Fundamental establece que la justicia debe ser impartida únicamente por los tribunales, siendo prohibida la creación de tribunales de excepción. Se instituye la división de poderes: «El Poder Judicial se ejerce por medio de procedimientos judiciales, del derecho civil, administrativo y

24 Decisión del Tribunal Constitucional de la Federación de Rusia de 12 de junio de 2013, № 27-P sobre el control de la constitucionalidad de las disposiciones del artículo 11, apartados 3 y 4 del párrafo cuarto del artículo 392 del Código de Procedimiento Civil de la Federación de Rusia en relación con la petición de la Presidencia del Tribunal del Distrito Militar de Leningrado. 
penal». De esta manera, el Tribunal Constitucional es parte del poder judicial y ninguna relación de jerarquía está establecida entre ellos y las dos jurisdicciones supremas rusas (Corte Suprema de la Federación Rusa y Corte Superior de Arbitraje de la Federación de Rusia).

Queda claro entonces que el Tribunal Constitucional es el único órgano competente para efectuar el control constitucional e interpretar la Constitución, empero esta reconoce a los sujetos de la Federación el derecho a establecer su propio sistema de los órganos de poder del Estado y establecer la regulación legal de su actividad.

\section{REFERENCIAS BIBLIOGRÁFICAS}

- Lesage. (1996). Rusia y el imperio de la ley, la norma legal y los acuerdos políticos, en el Estado de Derecho. Ensayos en honor de Guy Braibant, París, Dalloz.

- Luchaire, (2008). Democracia por el Derecho. Presentación de la Comisión de Venecia. En democracia y libertad: la tensión, el diálogo, la confrontación. Ensayos en honor de Slobodan Milacic, Bruselas, Bruylant.

- Claret. (1998). El Consejo de Europa: estándar europeo para la política de derechos fundamentales. En Milacic S. La Democracia Constitucional en Europa Central y Oriental (ed.): Evaluación y perspectivas, Bruselas, Bruylant.

- Furrer. El requisito del Consejo de Europa frente a los problemas de derechos humanos. En Milacic S. (ed.), La democracia en América Central y Este. Las evaluaciones y perspectivas.

- Tumanov. V. (2006). Sobre las características de la Constitución rusa. El imperio de la ley de este a oeste. Mezclas ofrecidas al profesor Michel Lesage, Sociedad de Legislación Comparada.

- Kellermann. A. (2005). El impacto de la ampliación de la UE a la Federación Rusa. Azerbaiyán y Rusia. Revista de Derecho Internacional y Comparado, vol. 1 (2).

- Kalinichenko, P. (2007). La aplicación del Acuerdo de colaboración y cooperación entre la Federación Rusa y la Unión Europea por los tribunales rusos. Zakon, № 11.

- Kovalkova, E. (2005). Principios de colaboración y cooperación, el ejemplo de las relaciones entre Rusia y la Unión Europea. Periódico Rossijskij, No. 3.

- Lochak D. (2002). Los derechos humanos, París, Le Découverte.

- Ley 1-CFL

- Ley No. 1-FKZ

- Ley No. 3132-1 